\title{
RESEARCH
}

Open Access

\section{Sex-differences in fine-scale home-range use in an upper-trophic level marine predator}

\author{
D. C. Lidgard ${ }^{1,2^{*}}$ (D, W. D. Bowen ${ }^{2}$ and S. J. Iverson ${ }^{1}$
}

\begin{abstract}
Background: The distribution of prey in the ocean is spatially and temporally patchy. How predators respond to this prey patchiness may have consequences on their foraging success, and thus physical condition. The recent ability to record fine-scale movements of marine animals combined with novel home-range analyses that incorporate the dimension of time should permit a better understanding of how individuals utilise different regions of space and the consequences on their foraging success.
\end{abstract}

Methods: Over a six-year study, we used T-LoCoH (Time-Local Convex Hull) home-range software to model archival GPS (Global Positioning System) data from 81 grey seals to investigate the fine-scale spatio-temporal use of space and the distribution of apparent foraging effort. Regions of home-ranges were classified according to the frequency of return visits (site fidelity) and duration of visits (intensity of use). Generalized linear mixed -effects models were used to test hypotheses on seasonal changes in foraging distribution and behaviour and the role of space-use and state on determining foraging success.

Results: Male grey seals had larger home-ranges and core areas than females, and both sexes showed a contraction in home-range and core area in fall leading up to the breeding season compared with summer. Heavier individuals had smaller core areas than lighter ones, suggesting access to higher quality habitat might be limited to those individuals with greater foraging experience and competitive ability. The size of the home-range or core area was not an important predictor of the rate of mass gain. A fine-scale spatio-temporal analysis of habitat use within the home-range provided evidence of intra-annual site fidelity at presumed foraging locations, suggesting predictably in prey distribution. Neither sex nor season were useful predictors for classifying behaviour. Rather, individual identity explained much of the variation in fine-scale behaviour.

Conclusions: Understanding how upper-trophic level marine predators use space provides opportunities to explore the consequences of variation in foraging tactics and their success on fitness. Having knowledge of the drivers that shape this intraspecific variation can contribute toward predicting how these predators may respond to both natural and man-made environmental forcing.

Keywords: T-LoCoH, Foraging behaviour, Marine mammal, Pinniped, Movement, Foraging ecology

\footnotetext{
* Correspondence: damian.lidgard@dal.ca

'Department of Biology, Dalhousie University, B3H 4J1, Halifax, Nova Scotia,

Canada

${ }^{2}$ Population Ecology Division, Bedford Institute of Oceanography,

Department of Fisheries and Oceans, Dartmouth, Nova Scotia B2Y 4A2,

Canada
}

(C) The Author(s). 2020 Open Access This article is distributed under the terms of the Creative Commons Attribution 4.0 International License (http://creativecommons.org/licenses/by/4.0/), which permits unrestricted use, distribution, and reproduction in any medium, provided you give appropriate credit to the original author(s) and the source, provide a link to the Creative Commons license, and indicate if changes were made. The Creative Commons Public Domain Dedication waiver (http://creativecommons.org/publicdomain/zero/1.0/) applies to the data made available in this article, unless otherwise stated. 


\section{Introduction}

The distribution of prey is typically spatially and temporally aggregated, particularly in the marine environment, driven by responses to environmental changes, predation pressure and reproductive status [1, 2]. Predators respond to the spatio-temporal heterogeneity in prey distribution by allocating their time at specific locations according to the area's intrinsic value [3]. As an example, marine predators that forage in the benthic zone, where the spatial and temporal variability in resources is often reduced, are likely to exhibit greater site fidelity than those that forage in the epipelagic zone where spatial variability is greater [4-6]. The response of predators to the distribution of prey is also governed by the costs of movement, competition and predation risks [7]. For example, in male ungulates, given the lack of paternal care, individuals trade-off forage quality with quantity when the costs of searching for high quality forage is costly due to scarcity or high interspecific competition [8]. Thus, movement patterns are the outcome of complex interactions between the environment and an individual's state, constrained by navigational capability [8-10]. How individuals respond to variability in prey distribution can have implications for their fitness [11-14].

The concept of a home-range $[15,16]$ has had enduring value and has led to the development of many statistical approaches to better understand how individuals use space [17-19]. Although the home-range defines the area used to satisfy essential functions such as foraging, home-range size per se tells us little about fine scale spatio-temporal movement that ought to reflect predator-prey interactions $[10,20,21]$. Rather, it depicts a homogenous space that fails to inform on how individuals allocate time to areas within the range [22].

GPS (Global Positioning System) telemetry can provide several, high accuracy location points per hour, even for marine species that spend a large proportion of their lives submerged [23]. Incorporating high resolution spatio-temporal data in movement analyses should lead to a better understanding of fine-scale habitat use [24-27] and interactions among conspecifics $[26,28]$. The inclusion of time in home-range analyses permits an examination of variation in temporal occurrence of an individual that likely reflect the heterogenous nature of resources within the home-range, and thus to define key habitats [29-31]. Areas that provide resources of relatively high quality or quantity are likely to be visited for extended periods of time (a measure of intensity of use) and revisited (a measure of site fidelity), the frequency of which being dependent on the profitability of the resource and the rate of replenishment [4]. Fine-scale spatial and temporal analyses also provide an opportunity to identify individual specialisation in foraging tactics and implications for fitness [11, 12, 32].

The grey seal (Halichoerus grypus) is an upper trophic-level marine predator that inhabits temperate waters on both sides of the North Atlantic Ocean. In the Northwest Atlantic, the grey seal has a broad continental shelf distribution from the Gulf of Maine north to the Gulf of St. Lawrence with the largest breeding colony on Sable Island [33]. Grey seals on Sable Island make repeated foraging trips to shallow offshore banks on the Eastern Scotian Shelf, with a few travelling into the Gulf of St. Lawrence and south to the Gulf of Maine [34-37]. Thus, many adults exhibit behaviour analogous to a central place forager. Grey seals are size-dimorphic and previous studies have shown sex differences in their diving behaviour, diet, movement patterns and at-sea distribution [34, 35, 38-44]. Males and females, respectively, greatly reduce or fast during the breeding season relying on energy stored in the form of blubber that was acquired in the months prior to breeding [38]. Thus, both sexes can be regarded as capital breeders and as such body mass gain during the months before the breeding season necessarily reflects overall foraging success.

We used high resolution spatio-temporal GPS data and a Time-Local Convex Hull (T-LoCoH) home-range model to examine fine-scale use of space by this upper trophic-level predator and the apparent consequences of behaviour on gain in body mass (an overall measure of foraging success).

\section{Methods}

We used a state-space behavioural switching model to estimate two behavioural states (travel vs. foraging) along each individuals GPS track. We then used T$\mathrm{LoCoH}$ to estimate home-range attributes and identify fine-scale patterns of occupancy with respect to these two behaviours within the home range. By incorporating a time-scaled distance metric into the analysis, one can identify movements that have a strong temporal component and areas that are spatially connected but temporally disconnected [31, 45, 46]. If we assume that seals allocate their time at specific locations according to the area's intrinsic value (e.g., prey patch profitability; 3 ), we should expect the frequency of visits to an area and the duration of stay to reflect the importance of the area to the individual. By including both behavioural and environmental attributes within a statistical framework, we aim to provide greater insight into the at-sea movements and habitat use of this large marine predator.

The study was conducted on Sable Island (Fig. 1). Sable Island is the world's largest grey seal breeding colony and is also used as a resting site throughout the year. The Island is located near the edge of the 


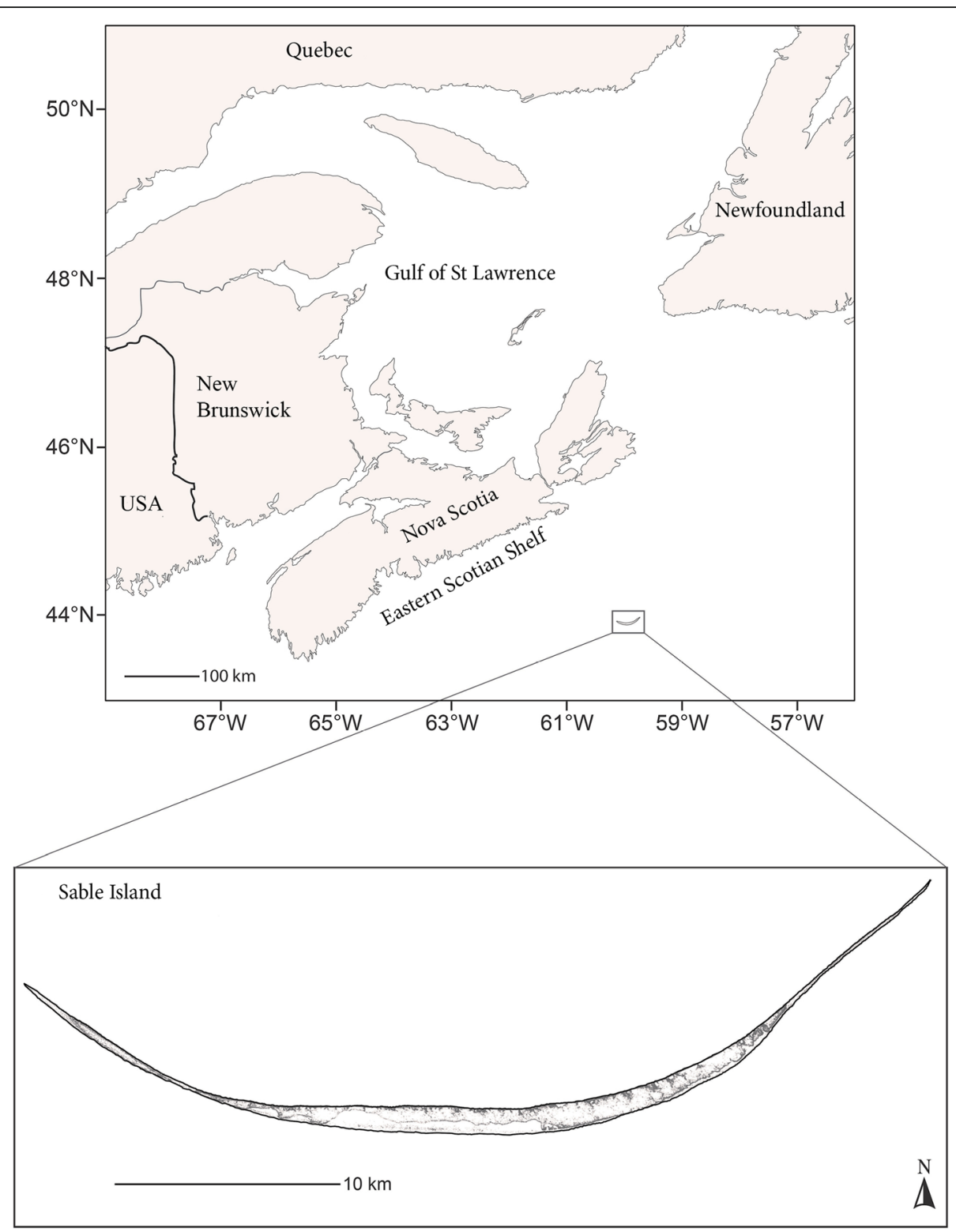

Fig. 1 Map showing the study area and Sable Island

continental shelf $\left(43^{\circ} 57^{\prime} 00^{\prime \prime} \mathrm{N}, 59^{\circ} 54^{\prime} 57^{\prime \prime} \mathrm{W}\right)$ on the Scotian shelf, Northwest Atlantic Ocean. The Scotian Shelf $\left(\sim 108,000 \mathrm{~km}^{2}\right)$ is comprised of a series of offshore shallow banks and basins separated by deep gullies and canyons [47] and is an important foraging area for grey seals [34]. Each year from 2009 to 2016, 15 to 20 mostly known-age adults were captured on land during the fall (September and October; 2009-2010) and in summer (June; 2011, 2013-2015) to attach electronic data loggers and telemetry tags. Tags were recovered the following December or January when the seals returned to the island to breed.

At each capture, seals were weighed using a $300 \mathrm{~kg}$ ( \pm $1 \mathrm{~kg}$ ) Salter spring balance (2009 to 2012) or a $500 \mathrm{~kg}$ ( \pm
$1 \mathrm{~kg}$ ) Tractel (www.tractel.com) load cell (2013 to 2015). Individuals were immobilised using the chemical anaesthetic Telazol (intra-muscular injection; males $0.45 \mathrm{mg}$ $\mathrm{kg}^{-1}$, females $0.90 \mathrm{mg} \mathrm{kg}^{-1}$ ) to allow attachment of tags and to accurately measure standard dorsal length. Each seal was fitted with a VHF transmitter $(164-165 \mathrm{MHz}$, www.atstrack.com), a Mk10-AF Fastloc ${ }^{\text {Tw }}$ GPS tag (www. wildlifecomputers.com) and a Vemco Mobile Transceiver (www.vemco.com), the latter of which was part of a concurrent study as in [36]. The tag mass burden at the time of initial capture was $0.27 \%$ of body mass for males and $0.33 \%$ for females. The VHF tag was used to locate animals on Sable Island after they had returned to the breeding colony. The MK10-AF tag was 
programmed to record and archive a GPS location every $15 \mathrm{~min}$. This corresponds to a location about every two dives on average [40]. GPS attempts were suspended when the unit was dry $>20 \mathrm{~min}$ and a location had been attained. The VHF transmitter was attached to the MK10-AF unit using a stainless-steel hose clamp and the whole unit was attached to the fur on the top of the head using a five-min epoxy [48].

\section{Body mass gain}

To determine the relationships among seasonal homerange size and body mass gain, body mass gain per day relative to initial body mass was calculated for individuals whose re-capture occurred soon after arrival to the breeding colony. For adult males $(n=21)$ and nonpregnant females $(n=8)$, the date of re-capture was operationally defined as the date of their arrival given that the island was searched daily both visually and using a VHF receiver. For females that had given birth $(n=30)$, although they may have been sighted earlier, the earliest date of weighing occurred at 3 days postpartum to allow time for the female to bond with her pup and thereby minimise the risks of abandonment. Although pregnant females may arrive on the island several days prior to parturition, we did not account for mass lost by females between arrival and parturition. Most of the female's mass loss is the result of lactation. Thus, for females weighed at 3-day postpartum, their mass on the day of parturition was estimated using average rates of female mass loss during lactation (4.1 $\left.\mathrm{kg} \mathrm{day}^{-1} ; 49\right)$.

\section{Data analysis}

Locations were calculated from archival GPS data using WC-DAP, a propriety software (www.wildlifecomputers. com) and archival ephemeris data (www.cddis.gsfc.nasa. gov). Locations acquired from $<5$ satellites, with a residual error $>30$, or considered outliers (sequential locations implying travel speed $\left.>10 \mathrm{~km} \mathrm{~h}^{-1}\right)$ were removed $(7.7 \%$ of locations) because of their lower accuracy $[49,50]$.

Seasonal changes in at-sea behaviour of grey seals have been observed in previous studies [34, 35, 44, 51]. Therefore, data were classified as summer (1 June to 30 September) or fall (1 October to 4 December). After $\sim 4$ December adults are returning to the breeding colony in increasing numbers, thus little time is spent at sea and foraging is essentially arrested. To obtain a measure of the likelihood of apparent foraging, a Hidden Markov Model (HMM) was used [52] with seal travel rate conditional upon two discrete, unobserved movement states: fast and slow movement. We assumed slow movement was associated with area restricted search (i.e., presumably foraging or resting behaviour) and characterised as high values of $p$ (ARS), probability of area-restricted search. Low p (ARS) values suggested behaviours such as travel. Details of the HMM can be found in [36].

To quantify the use of space by individuals, we used Time-Local Convex Hull (T-LoCoH) home-range software implemented in $R$ [46]. T-LoCoH is a nonparametric method for estimating home-ranges and exploring spatio-temporal patterns in movement from large GPS datasets with fine-scale temporal continuity. Utilization distributions are created from spatially and temporally defined hulls, i.e. minimum convex polygons $[31,45,46]$. Hulls are generated from each GPS location (the parent point) and neighbouring points identified according to their temporal and spatial relatedness to the parent point (Fig. 2a \& b). Time is incorporated into the creation of hulls through a time-scaled distance measure $(s)$, defined according to the maximum theoretical velocity of the animal, that transforms the time interval between any two locations into a third axis of Euclidean space. This measure is used to identify the number of neighbouring points within a hull that are correlated to the parent point with respect to time and space; if $s=0$ then time plays no role in selecting neighbouring points and utilization distributions are created using the traditional space-use model. As $s$ increases in value, the duration of time between successive points plays a greater role in identifying neighbouring points and creating hulls. Given that we were interested in individual variation, the chosen value of $s$ was based on an evaluation of each individual's data. We used the graphical tools available in the T-LoCoH software to visualize the relationship between the percentage of hulls that are time selected and $s$. As recommended [31], we selected a value of $s$ that allowed 40 to $80 \%$ of all hulls to be time selected (the value of $s$ varied between 0.03 and 0.10 ).

Changes in travel rate presumably reflect changes in behaviour. Thus, the number of GPS locations collected per unit area will also change. When foraging or resting, seals are likely to move within a relatively small area thus there will be more locations per unit area, whereas when travelling seals will move faster and generate fewer data points across a larger area. Therefore, hulls were generated from neighbouring data points using the adaptive method, as recommended by Lyons et al. [31, 46]. Using this approach, neighbour points were selected until the cumulative distance (in metres) between each neighbour and the parent point was less than or equal to a defined limit, $a$. The method is referred to as adaptive since it allows more data points to be selected, and thus more detail acquired, when the animal is moving within a small area, and fewer points when the seal is moving fast through an area in a directional manner. The choice of $a$ is crucial since if the value chosen is too small, there is a heightened probability of a type I error (not including areas used by the animal) while a value too large will increase the likelihood of a 


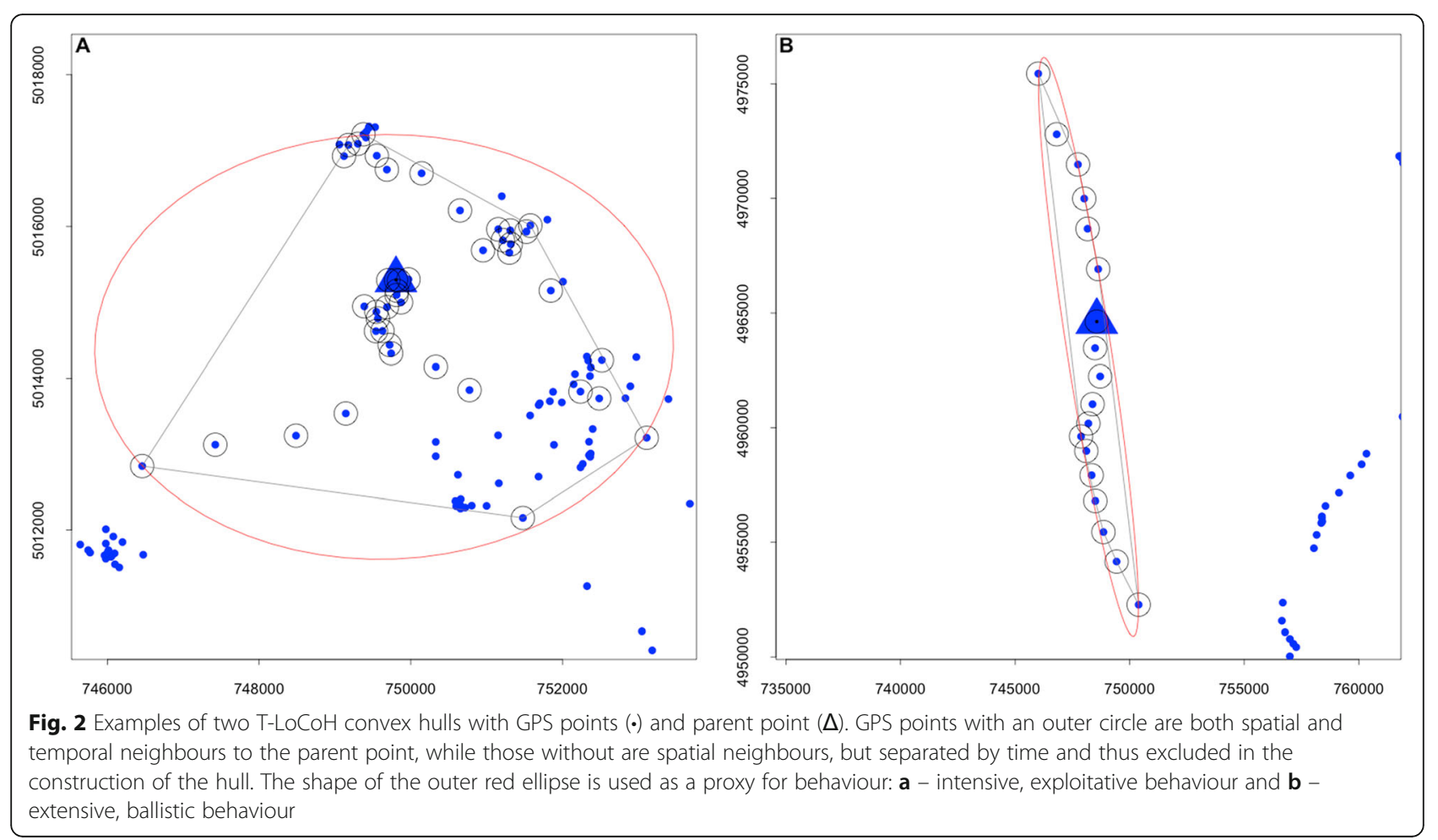

type II error (including areas not used). To define $a$ for each individual, we first generated a range of $a$ values. To ensure we created a suitable range, we first identified the most appropriate number of nearest neighbours, $k$, as a starting point. Since we were unsure as to what was appropriate we chose a wide range (6-24 points) and then grouped them into isopleths. To identify the most suitable value of $k$, plots of isopleth area and isopleth edge:area for different values of $k$ were constructed. Large jumps in the isopleth area (or edge:area) indicated a high risk of a type II error, thus values of $k$ were chosen at the point when the isopleth area (and edge:area) had stabilised. For all individuals, $k=15$ was found to be the most appropriate value. The number of nearest neighbours was then refined using the adaptive method. First, the value of $a$ was calculated for $k=15\left(\mathrm{a}_{\mathrm{k} 15}\right)$. To identify the critical value of $a$, a range of $a$ values was defined centred around $\mathrm{a}_{\mathrm{k} 15}$. Then, for each value of $a$, nearest neighbours were selected, hulls generated and ordered from smallest to largest point density and grouped into isopleths. The same procedure for choosing the value of $k$ was followed for choosing the most appropriate value of $a$, i.e. plotting isopleth area and area:edge for different values of $a$. Once values of $s$ and $a$ were set for each individual, several metrics associated with each hull were calculated (Table 1).

Based on [43], a seal was said to have made a return visit to a hull if the seal had been outside of the hull for more than $12 \mathrm{~h}$.

Table 1 Descriptions of hull metrics used to describe the behaviour of grey seals, Sable Island

\begin{tabular}{|c|c|}
\hline Name & Description \\
\hline core area & $\begin{array}{l}\text { an indication of high value resource areas. Core areas were created by sorting } \\
\text { hulls by the number of visits. Hulls were then merged until } 30 \% \text { of data points } \\
\text { were contained }\end{array}$ \\
\hline eccentricity & $\begin{array}{l}\text { a measure of the shape of each hull, varying from } 0 \text { to } 1 \\
0 \text { - approximates a circle, i.e. intensive, exploitative behaviour } \\
1 \text { - a straight line, i.e. extensive, ballistic behaviour }\end{array}$ \\
\hline number of single visits to a hull & values $>1$ are return visits and used as a proxy for site fidelity \\
\hline normalized number of single visits to a hull & number of single visits to a hull, $\mathrm{km}^{-2}$ \\
\hline mean number of locations per visit to a hull & used as a proxy for residency \\
\hline normalized number of locations per visit to a hull & mean number of locations per visit to a hull, $\mathrm{km}^{-2}$ \\
\hline probability of area-restricted search & a modelled behavioural measure that reflects the likelihood of apparent foraging \\
\hline
\end{tabular}


Individual home-ranges based on the 95\% isopleth for each season were calculated by sorting hulls according to the density of data points and then merging hulls until $95 \%$ of data points were included. To identify core areas within the home-range, we assumed areas with a higher number of repeat visits were favoured areas. We chose a $30 \%$ isopleth to identify these areas since we wanted to be conservative in selecting key resource areas and this value has been chosen in other studies (e.g., [30, $53,54])$. Thus, rather than using the number of locations to sort hulls, the visitation frequency (nsv) was used and hulls merged until $30 \%$ of data points were contained, i.e. the $30 \%$ isopleth. Given that grey seals are benthic foragers and known to spend time at offshore banks, we examined the importance of travel distance and water depth on the choice of foraging area. Although use of space could also reflect the risk of predation, adult grey seals in this population have few natural predators and therefore we hypothesize that their use of space is more likely to reflect foraging decisions. For each GPS point distance to Sable Island and bathymetry (one-minute resolution [55]) were estimated.

Linear mixed-effects models ( $\mathrm{R}$ package lme4: [56]) were used to evaluate the importance of predictor variables (body mass, body mass gain, sex and season and their interaction) on home-range size. Seal identity was used as a random intercept. Residual plots were used to determine violations of homoscedasticity and normality. Model selection was implemented using $\mathrm{AICc}, \Delta \mathrm{AIC}_{\mathrm{c}}$, weights and the evidence ratio, ER $[57,58]$. Goodness of fit estimates $\left(R^{2}\right)$ for linear mixed effects models [59] are provided using $\mathrm{R}$ package piecewiseSEM [60]. The median absolute residual (mad) and standard error (se) are reported as the measures of variability. Statistical analyses and plots were conducted using $\mathrm{R}$ v3.3.2 [61].

\section{Results}

One hundred and nineteen seals were instrumented. Of those, 102 (86\%) returned to Sable Island during the following breeding season and their satellite/GPS transmitter recovered. Due to instrument malfunction, the quality of GPS data from 21 (three in 2011 and 18 in 2012) instruments were insufficient for fine-scale analyses. Thus, data were available from 81 instrumented animals (see Additional file 1). Seals were studied for an average of $192.5 \pm 12.9$ days. For those individuals of known age, the mean age of males $(n=17)$ and females $(n=53)$ was $17.5 \pm 5.0$ years $(\mathrm{CV}=28.6 \%)$ and $24.6 \pm 4.5$ years $(\mathrm{CV}=18.3 \%)$, respectively. Mean mass at deployment (mean $\pm \mathrm{sd})$ for males $(n=21)$ and females $(n=60)$ was $209.0 \pm 36.6 \mathrm{~kg} \quad(\mathrm{CV}=17.5 \%)$ and $164.0 \pm 24.9 \mathrm{~kg}$ $(\mathrm{CV}=15.2 \%)$, respectively. In all years, the movement of seals was confined to the Eastern Scotian Shelf and the southern Gulf of St. Lawrence with most seals using the former during repeated trips to and from Sable Island.

\section{Predictors of home-range}

Season and sex were the best predictors of the 95\% home-range size (Table 2; see Additional file 2). Body mass and a body mass-sex interaction were additional predictors in alternative models, however given the greater complexity of these models and the relatively high evidence ratio for the body mass-sex interaction model $(E R=1.79)$, the season-sex model was preferred. The model accounted for $58.4 \%$ of the variance $\left(R_{\text {GLMM(c) })}^{2}\right.$ while the fixed effects alone accounted for $30.6 \%\left(\mathrm{R}_{\mathrm{GLMM}(\mathrm{m})}^{2}\right)$. The size of the $95 \%$ home-range area was greater in male grey seals than females, and for both sexes, the home-range contracted during the fall period prior to the breeding season (Table 3).

Fixed effects of each candidate model are body mass at deployment $(\mathrm{Bm})$, season $(\mathrm{Sn})$ and sex $(\mathrm{Sx})$. Variables for model selection are Akaike's information criteria (AICc, $\Delta \mathrm{AIC}_{\mathrm{c}}$ ), Akaike weights (w) and log likelihood (LL). For all models, $\mathrm{N}_{\text {seals }}=81, \mathrm{~N}_{\mathrm{obs}}=126$.

Body mass, season, sex and the interactions body mass * sex and season * sex were the best predictors of the size of the core area (Table 4; see Additional file 3; $\left.\mathrm{R}_{\mathrm{GLMM}(\mathrm{c})}^{2}=18.5 \% ; \mathrm{R}_{\mathrm{GLMM}(\mathrm{m})}^{2}=18.5 \%\right)$. Males had a larger core area than females and in both sexes the core area contracted during the fall period with males experiencing a higher magnitude of change than females (Table 5). The core area decreased in size with body mass in both sexes.

The core area is defined as the $30 \%$ isopleth based on number of visits to a hull. Fixed effects of each candidate

Table 2 Linear mixed-effects models for 95\% home-range area of grey seals, Sable Island, Nova Scotia, 2009-2011 and 20132015

\begin{tabular}{llllll}
\hline Model & $\mathrm{K}$ & $\mathrm{AlC}_{\mathrm{c}}$ & $\Delta \mathrm{AIC}$ & $\mathrm{w}$ & $\mathrm{LL}$ \\
\hline $\mathrm{Bm}+\mathrm{Sn}+\mathrm{Sx}+\mathrm{Bm}{ }^{*} \mathrm{Sx}$ & 7 & -34.1 & 0 & 0.36 & 24.5 \\
$\mathrm{Bm}+\mathrm{Sn}+\mathrm{Sx}$ & 6 & -32.9 & 1.16 & 0.20 & 22.8 \\
$\mathrm{Sn}+\mathrm{Sx}$ & 5 & -32.8 & 1.24 & 0.19 & 21.7 \\
$\mathrm{Bm}+\mathrm{Sn}+\mathrm{Sx}+\mathrm{Sn}{ }^{*} \mathrm{Sx}+\mathrm{Bm} * \mathrm{Sx}$ & 8 & -31.8 & 2.27 & 0.12 & 24.5 \\
$\mathrm{Bm}+\mathrm{Sn}+\mathrm{Sx}+\mathrm{Sn}{ }^{*} \mathrm{Sx}$ & 7 & -30.8 & 3.27 & 0.07 & 22.9 \\
$\mathrm{Sn}+\mathrm{Sx}+\mathrm{Sn} * \mathrm{Sx}$ & 6 & -30.7 & 3.35 & 0.07 & 21.7 \\
$\mathrm{Sn}$ & 4 & -15.3 & 18.8 & 0 & 11.8 \\
$\mathrm{Bm}+\mathrm{Sn}$ & 5 & -14.9 & 19.2 & 0 & 12.7 \\
$\mathrm{Bm}+\mathrm{Sx}+\mathrm{Bm} * \mathrm{Sx}$ & 6 & -3.40 & 30.7 & 0 & 8.03 \\
$\mathrm{Bm}+\mathrm{Sx}$ & 5 & -2.90 & 31.1 & 0 & 6.72 \\
$\mathrm{Sx}$ & 4 & 0.20 & 34.3 & 0 & 4.04 \\
$\sim$ & 3 & 13.8 & 47.9 & 0 & -3.82 \\
$\mathrm{Bm}$ & 4 & 15.7 & 49.8 & 0 & -3.71 \\
\hline
\end{tabular}


Table 3 The 95\% home-range $\left(\mathrm{km}^{2}\right)$ for male and female grey seals during the summer and fall periods, Sable Island, Nova Scotia, 2009-2011 and 2013-2015

\begin{tabular}{lcccccccc}
\hline & \multicolumn{2}{l}{ Summer } & & & & Fall & & \\
\cline { 2 - 3 } sex & median, $\mathrm{km}^{2}$ & mad & $\mathrm{n}$ & & median, $\mathrm{km}^{2}$ & mad & $\mathrm{n}$ \\
\hline Male & 3260 & 788 & 10 & & 2204 & 1149 & 20 \\
Female & 2092 & 1283 & 37 & & 1171 & 511 & 59 \\
\hline
\end{tabular}

mad median absolute deviation.

model are body mass at deployment $(\mathrm{Bm})$, season $(\mathrm{Sn})$ and sex (Sx). Variables for model selection are Akaike's information criteria (AICc, $\triangle \mathrm{AIC}_{\mathrm{c}}$ ), Akaike weights (w) and $\log$ likelihood (LL). For all models, $\mathrm{N}_{\text {seals }}=81, \mathrm{~N}_{\text {obs }}=$ 126.

The core area is defined as the $30 \%$ isopleth based on number of visits to a hull. Mad=median absolute deviation.

\section{Predictors of body mass gain}

During the combined summer and fall periods, males $(n=21)$ gained $0.30 \%$ of their initial mass per day $(\mathrm{mad}=0.13)$ while females $(n=38)$ gained $0.22 \%$ per day $(\operatorname{mad}=0.11)$. Sex was the best predictor of body mass gain $\left(R^{2}=14 \%\right.$; Table 6 a \& b; see Additional file 4). Neither, the $95 \%$ home-range (Table 6 a) nor core-area (Table $6 \mathrm{~b}$ ) were good predictors of mass gain.

\section{Spatio-temporal use within the home-range}

Grey seals often returned to areas previously visited within their home range. The frequency distribution of visits to locations was strongly positively skewed suggesting preference for some areas over others (Fig. 3a). The amount of time spent at a location (Fig. 3b) was also

Table 4 Linear mixed-effects models for size of the core area of grey seals, Sable Island, Nova Scotia, 2009-2011 and 2013-2015

\begin{tabular}{llllll}
\hline Model & $\mathrm{K}$ & $\mathrm{AlC}_{c}$ & $\Delta \mathrm{AIC}_{c}$ & $\mathrm{w}$ & $\mathrm{LL}$ \\
\hline $\mathrm{Bm}+\mathrm{Sn}+\mathrm{Sx}+\mathrm{Sn}{ }^{*} \mathrm{Sx}+\mathrm{Bm}{ }^{*} \mathrm{Sx}$ & 8 & 92.7 & 0 & 0.64 & 37.7 \\
$\mathrm{Bm}+\mathrm{Sn}+\mathrm{Sx}+\mathrm{Bm}{ }^{*} \mathrm{Sx}$ & 7 & 96.0 & 3.38 & 0.12 & -40.5 \\
$\mathrm{Bm}+\mathrm{Sn}+\mathrm{Sx}+\mathrm{Sn}{ }^{*} \mathrm{Sx}$ & 7 & 96.2 & 3.51 & 0.11 & -40.6 \\
$\mathrm{Bm}+\mathrm{Sn}+\mathrm{Sx}$ & 6 & 97.7 & 5.03 & 0.05 & -42.5 \\
$\mathrm{Sn}+\mathrm{Sx}+\mathrm{Sn}{ }^{*} \mathrm{Sx}$ & 6 & 98.3 & 5.66 & 0.04 & -42.8 \\
$\mathrm{Sn}+\mathrm{Sx}$ & 5 & 100.2 & 7.54 & 0.02 & -44.8 \\
$\mathrm{Bm}+\mathrm{Sx}+\mathrm{Bm}{ }^{*} \mathrm{Sx}$ & 6 & 100.8 & 8.16 & 0.01 & -44.1 \\
$\mathrm{Sn}$ & 4 & 101.7 & 9.02 & 0.01 & -46.7 \\
$\mathrm{Bm}+\mathrm{Sx}$ & 5 & 102.0 & 9.38 & 0.01 & -45.8 \\
$\mathrm{Bm}+\mathrm{Sn}$ & 5 & 103.5 & 10.81 & $<0.01$ & -46.5 \\
$\mathrm{Sx}$ & 4 & 106.3 & 13.65 & $<0.01$ & -49.0 \\
$\sim$ & 3 & 107.3 & 14.61 & 0 & -50.5 \\
$\mathrm{Bm}$ & 4 & 108.3 & 15.66 & 0 & -50.0 \\
\hline
\end{tabular}

Table 5 The 30\% core home-range $\left(\mathrm{km}^{2}\right)$ for male and female grey seals during the summer and fall periods, Sable Island, Nova Scotia, 2009-2011 and 2013-2015

\begin{tabular}{|c|c|c|c|c|c|c|}
\hline \multirow[b]{2}{*}{ sex } & \multicolumn{3}{|l|}{ Summer } & \multicolumn{3}{|l|}{ Fall } \\
\hline & median, $\mathrm{km}^{2}$ & mad & $\bar{n}$ & median, $\mathrm{km}^{2}$ & mad & $\bar{n}$ \\
\hline Male & 379.0 & 213.0 & 10 & 168.3 & 81.3 & 20 \\
\hline Female & 230.0 & 235.6 & 37 & 132.6 & 62.5 & 59 \\
\hline
\end{tabular}

strongly positively skewed, indicating differential use and suggesting that some areas were preferred over others. Overall, the broad distributions of both frequency and duration of visits to hulls suggest that seals were exhibiting multiple behaviours while at sea.

To examine this hypothesis, we defined six behavioural categories based on visit frequency and duration to a hull (see Additional file 5). We used the first and third quartiles of the normalized number of visits to a single hull (see Table 1 for definition; 0.14 and 0.89 visits per $\mathrm{km}^{2}$, respectively) to split behaviour into three categories: infrequent, frequent and very frequent visits to the same hull. Then, each of the three visitation frequency categories was split again according to the median of the normalized number of locations per visit (see Table 1 for definition; $0.85,1.46$, and 3.31 locations per $\mathrm{km}^{2}$, respectively). Hulls within the vicinity of Sable Island had high frequency of return visits of short duration presumably representing short repeated movements of seals near the island. To avoid biasing data with these

Table 6 Linear models for relative body mass gain (a: 95\% home range and sex; b: core area and sex) of grey seals, Sable Island, Nova Scotia, 2009-2011 and 2013-2015

\begin{tabular}{lccccc}
\hline Model & $\mathrm{K}$ & $\mathrm{AlC}_{\mathrm{c}}$ & $\Delta \mathrm{AIC}_{\mathrm{c}}$ & $\mathrm{W}$ & $\mathrm{LL}$ \\
\hline & & $\mathrm{a}$ & & & \\
$\mathrm{Sx}$ & 3 & -197.1 & 0 & 0.67 & 101.8 \\
$\mathrm{Hr}+\mathrm{Sx}$ & 4 & -195.0 & 2.11 & 0.24 & 101.9 \\
$\mathrm{Hr}+\mathrm{Sx}+\mathrm{Hr}{ }^{*} \mathrm{Sx}$ & 5 & -192.6 & 4.48 & 0.07 & 101.9 \\
$\sim$ & 2 & -189.6 & 7.54 & 0.02 & 96.9 \\
$\mathrm{Hr}$ & 3 & -187.4 & 9.77 & 0.01 & 97.0 \\
$\mathrm{~b}$ & & & & & \\
$\mathrm{Sx}$ & 3 & -197.1 & 0 & 0.58 & 101.8 \\
$\mathrm{Ca}+\mathrm{Sx}+\mathrm{Ca} * \mathrm{Sx}$ & 5 & -195.2 & 1.91 & 0.22 & 103.2 \\
$\mathrm{Ca}+\mathrm{Sx}$ & 4 & -194.8 & 2.29 & 0.18 & 102.0 \\
$\sim$ & 2 & -189.6 & 7.54 & 0.01 & 96.9 \\
$\mathrm{Ca}$ & 3 & -187.6 & 9.48 & 0.01 & 97.0 \\
\hline
\end{tabular}

Fixed effects of each candidate model are a) $95 \%$ home-range area $(\mathrm{Hr})$ and sex (Sx); b) core area (Ca) defined as the $30 \%$ isopleth based on number of visits to a hull, and sex (Sx). $N_{\text {seal }}=59$. Variables for model selection are Akaike's information criteria (AICc, $\triangle \mathrm{AIC} \mathrm{C}_{\mathrm{c}}$, Akaike weights (w) and log likelihood (LL) 

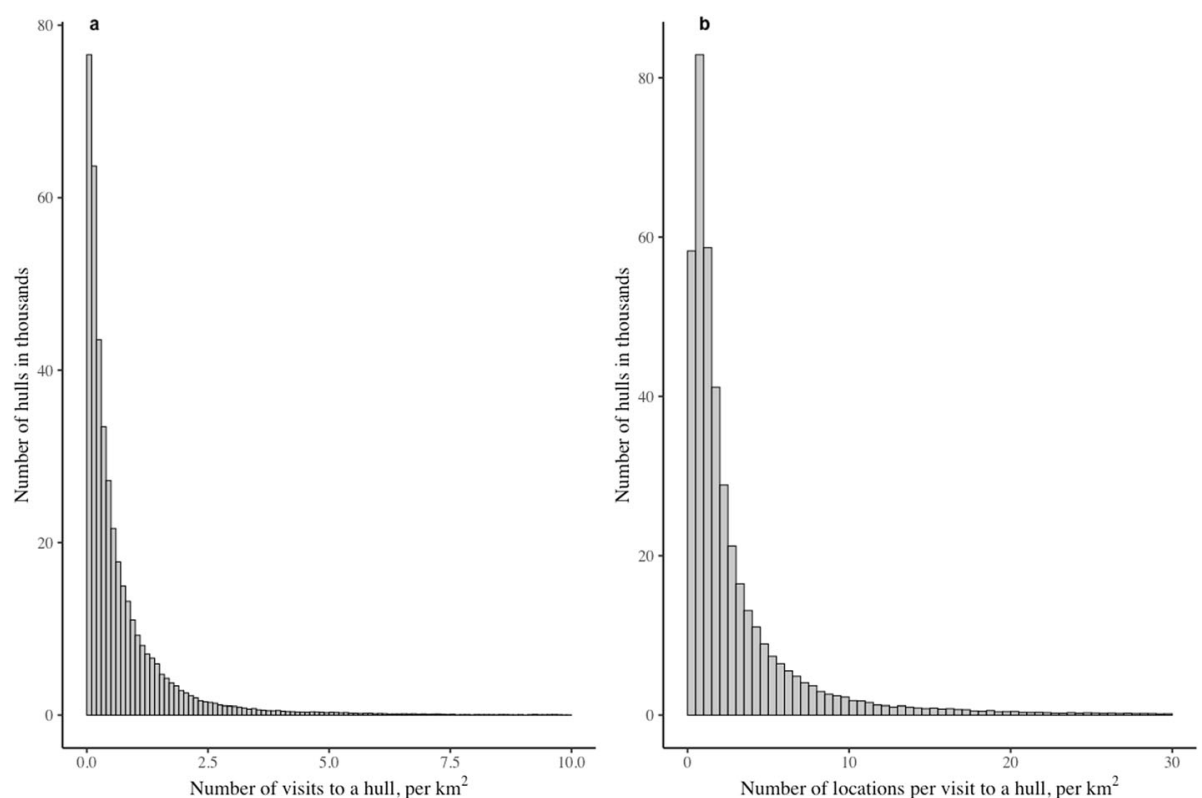

Fig. 3 A histogram of (a) the normalised number of visits to a hull per $\mathrm{km}^{2}$ and (b) the normalised number of locations within a hull per $\mathrm{km}{ }^{2}$ for grey seals $(n=81)$, Sable Island, Nova Scotia

frequent short trips, GPS points that were within $15 \mathrm{~km}$ of Sable Island were excluded from this analysis.

Seal behaviour in a hull, represented by eccentricity (Fig. 4a) and modelled behavioural state (Fig. 4b), showed wide variation both within and among the six behaviour categories. The shape of hulls for which seals visited infrequently (i.e., those in behaviour categories 1 and 2), tended to be more eccentric suggesting travel.
The probability of area-restricted search was highest for those hulls within category 6 which had the highest frequency of return visits and the longest duration within the hull (see Additional file 5). Hulls in categories 4 and 5 also had relatively high values of apparent foraging, but there was much greater variability suggesting other behaviours as well. We hypothesized that hulls with the fewest return visits (behavioural categories 1 to 2) were
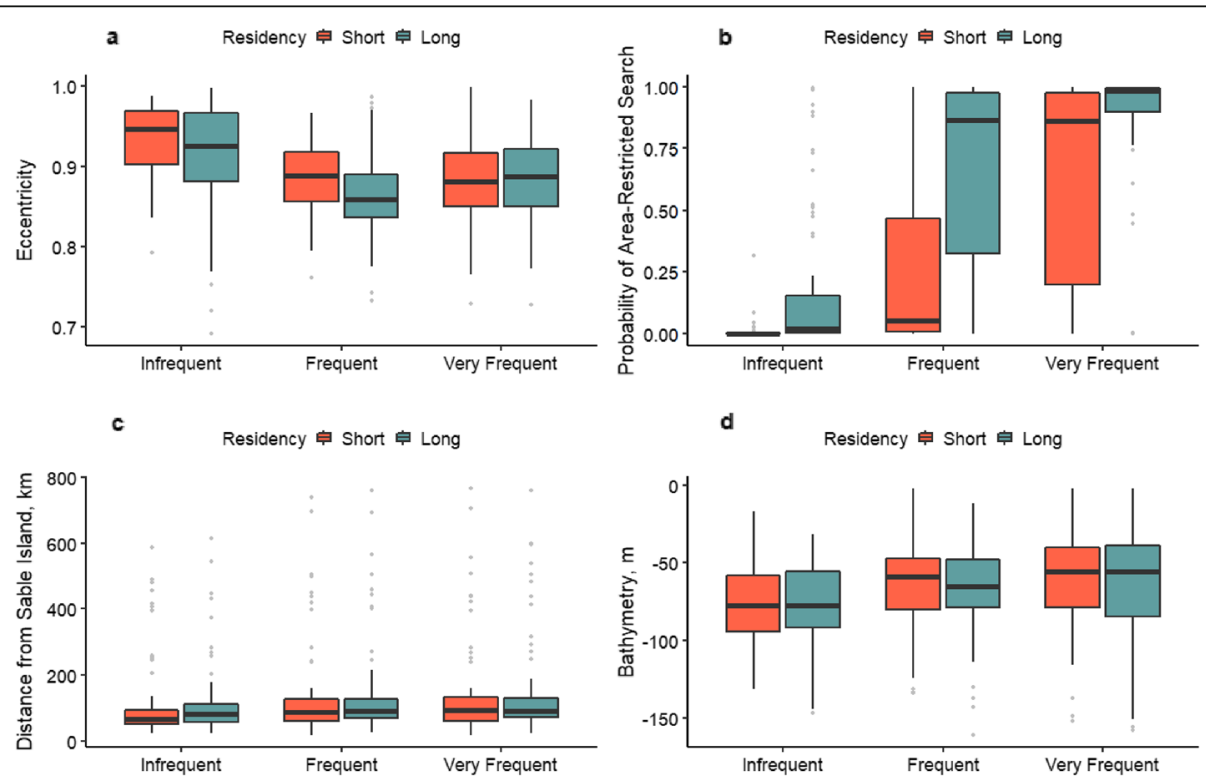

Fig. 4 Metrics describing the characteristics of hulls for grey seals $(n=81)$, Sable Island, Nova Scotia. a , eccentricity; b , probability of arearestricted search; $\mathbf{c}$, distance from Sable Island; $\mathbf{d}$, bathymetry. Hulls were classified according to the number of visits to and number of locations within a hull 
most likely associated with travel while those with the most return visits (categories 5 to 6 ) were most likely associated with foraging. For both sexes, hulls within categories 5 to 6 tended to occur over offshore banks relatively close to Sable Island (Additional file 6 a \& b).

Much of the seals' activities occurred within $\sim 150 \mathrm{~km}$ of Sable Island (Fig. 4c). The depth of water for hulls visited by seals fell between $50 \mathrm{~m}$ and $75 \mathrm{~m}$, indicating that seals spent considerable time at shallow offshore banks (Fig. 4d). Variability in the distance from Sable Island and bathymetry was high within, but less variable among categories (Fig. 4c and d).

The proportion of time seals spent in hulls within each of the six categories appeared to be governed by the frequency of return visits to the hull (Fig. $5 ; \mathrm{F}_{2,237}=188.3$, $p<0.001)$ and was not driven by sex $\left(\mathrm{F}_{1,237}=0.300, p=\right.$ $0.585)$. Seals spent the greatest proportion of time in hulls with frequent re-visitation (i.e., categories 3 and 4; median $=0.627, \operatorname{mad}=0.132 ;$ Tukey post-hoc, all $p$ values $<0.0001$ ), and the least proportion of time in hulls with infrequent re-visitation (i.e., categories 1 and 2 ; median $=0.103, \operatorname{mad}=0.078$; Tukey post-hoc, all $\mathrm{p}$ values $<0.0001)$. There was also a significant seasonal interaction $\left(\mathrm{F}_{2,258}=10.5, \mathrm{p}<0.001\right)$. First, the pattern observed above was apparent in both the summer and fall seasons (Tukey post-hoc, all $\mathrm{p}$ values $<0.0001$ ). However, during the summer seals spent a greater proportion of time in hulls with infrequent re-visitation compared with the fall (summer: median $=0.160$, $\operatorname{mad}=0.120$; fall: median $=0.094$, $\operatorname{mad}=0.065$ ), and a lower proportion of time in hulls with very frequent re-visitation (summer: median $=0.135, \operatorname{mad}=0.178 ;$ fall: median $=0.178, \operatorname{mad}=$ 0.212 ; Tukey post-hoc, all $\mathrm{p}$ values $<0.05$ ).

The duration of time spent in hulls of categories 5 and 6 (i.e., very frequent visitation) was highly variable among individuals (median $=5.5 \mathrm{~h}$; $\operatorname{mad}=3.5 \mathrm{~h}$ ). Body mass, season and sex were included in models that were equally as useful at predicting the time spent in categories 5 and 6 as the intercept model, thus we chose the most parsimonious model (Table 7: see Additional file 6 a). Time spent in hulls associated with categories 5 to 6 was also not a good predictor of the relative rate of mass gain. In agreement with earlier analyses, sex was the best predictor (Table 8: see Additional file $6 \mathrm{~b}$ ).

We plotted contrasting movement tracks of three adult female grey seals to illustrate the geographical distribution of hulls categorized by behaviour. Hulls within behavioural categories 1 and 2 (infrequent visitation), occurred closer to Sable Island and tended to form linear sequences of locations (Fig. 6 a-c). In contrast, hulls within behaviour categories 5 and 6 (very frequent visitation), tended to cluster over offshore banks (e.g., Middle, Banquereau and Sable Island Banks) (Fig. 6 a-c). Hulls within categories 3 and 4 (frequent visitation) likely comprised multiple behaviours with some hulls occurring in linear sequences while others appear clustered.

\section{Discussion}

We collected GPS location data every $\sim 15 \mathrm{~min}$, which represented a location every two to three dives. Such high-resolution data provided the opportunity to

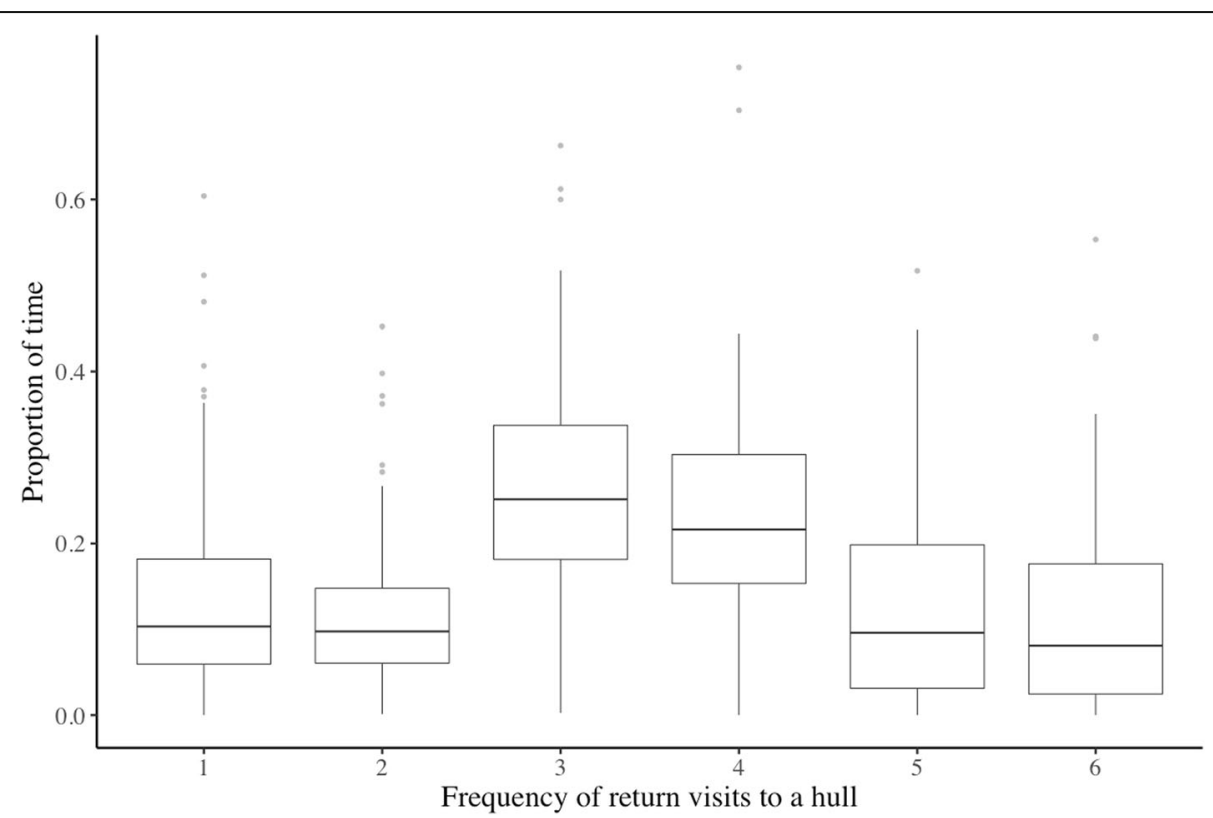

Fig. 5 Proportion of time grey seals $(n=81)$ spent in hulls within behavioural categories 1 to 6, 2009-2011 and 2013-2015 
Table 7 Linear models for proportion of time spent in hulls within categories 5 to 6 (very frequent visitation) for grey seals, Sable Island, Nova Scotia, 2009-2011 and 2013-2015

\begin{tabular}{|c|c|c|c|c|c|}
\hline Model & K & $\mathrm{AlC}_{\mathrm{c}}$ & $\triangle \mathrm{AlC}_{\mathrm{c}}$ & w & $\mathrm{LL}$ \\
\hline $\mathrm{Bm}$ & 3 & -90.1 & 0 & 0.21 & 48.2 \\
\hline $\mathrm{Bm}+\mathrm{Sn}$ & 4 & -89.8 & 0.31 & 0.18 & 49.1 \\
\hline$\sim$ & 2 & -89.5 & 0.64 & 0.15 & 46.8 \\
\hline Sx & 3 & -88.8 & 1.38 & 0.1 & 47.5 \\
\hline Sn & 3 & -88.5 & 1.64 & 0.09 & 47.4 \\
\hline$B m+S x$ & 4 & -88.1 & 2.07 & 0.07 & 48.2 \\
\hline$S x+S n$ & 4 & -87.9 & 2.25 & 0.07 & 48.1 \\
\hline$S n+S x+B m$ & 5 & -87.7 & 2.44 & 0.06 & 49.1 \\
\hline$S n+S x+S n * S x$ & 5 & -87.0 & 3.14 & 0.04 & 48.8 \\
\hline$B m+S n+S x+S n * S x$ & 6 & -86.6 & 3.54 & 0.04 & 49.7 \\
\hline
\end{tabular}

Fixed effects of each candidate model are body mass at deployment $(\mathrm{Bm})$ and $\operatorname{sex}(\mathrm{S} x), \mathrm{N}_{\text {seals }}=81$. Variables for model selection are Akaike's information criteria (AICC, $\triangle \mathrm{AIC}$ ), Akaike weights (w) and log likelihood (LL)

examine movement and habitat use of a marine predator on a fine-scale. To take advantage of these highresolution data, we used an adaptive non-parametric home-range model, T-LoCoH [31], that incorporates time into the construction of minimum convex hulls around each GPS point. The inclusion of time allowed us to identify areas within the home-range according to their intensity and pattern of use, both of which may serve as an indication of variation in habitat quality [30, 62].

The 95\% home-range size of male and female grey seals was considerably smaller in this study compared with a previous study on the same population [63]. However, the earlier study used location data derived from ARGOS to estimate movement trajectories and fixed-kernel home-range estimators, both of which are known to overestimate home-range size $[46,49,64]$. Nevertheless, it is also possible that the increase in the size of the Sable Island grey seal population [33] and associated increase in intraspecific competition [51, 65]

Table 8 Linear models for relative body mass gain and proportion of time spent in hulls within categories 5 to 6 for grey seals, Sable Island, Nova Scotia, 2009-2011 and 2013-2015

\begin{tabular}{llllll}
\hline Model & $\mathrm{K}$ & $\mathrm{AlC}_{\mathrm{c}}$ & $\Delta \mathrm{AIC}_{\mathrm{c}}$ & $\mathrm{w}$ & $\mathrm{LL}$ \\
\hline $\mathrm{S} x$ & 3 & -202.9 & 0 & 0.68 & 104.7 \\
$\mathrm{~S} x+\mathrm{t}_{5,6}$ & 4 & -200.7 & 2.21 & 0.23 & 104.7 \\
$\mathrm{~S} x+\mathrm{t}_{5,6}+\mathrm{Sx}^{*} \mathrm{t}_{5,6}$ & 5 & -198.6 & 4.37 & 0.08 & 104.8 \\
$\sim$ & 2 & -194.7 & 8.23 & 0.01 & 99.5 \\
$\mathrm{t}_{5,6}$ & 3 & -193.1 & 9.79 & 0.01 & 99.8 \\
\hline
\end{tabular}

Fixed effects of candidate model are time spent in hulls within categories 5 to $6\left(t_{5,6}\right), N_{\text {seals }}=59$. Variables for model selection are Akaike's information criteria (AIC $C_{c} \Delta \mathrm{AIC} C_{c}$, Akaike weights (w) and log likelihood (LL) may have contributed to changes in home-range size over time.

The ability to assess the extent and variability of space use in pinnipeds is governed by the duration of deployments and the number of animals in the study. Pinnipeds undergo an annual moult thus limiting the length of deployments and the ability to measure the full extent of individual movements. In this study, the majority of individuals wore tracking instruments for the period immediately following the moult and up to the start of the breeding season, providing the maximum recording period (6-7 months). Recent studies have highlighted the need for large sample sizes (10 to 100) when estimating utilization distributions due to the high variability in movement behaviour among individuals of a given species [66-68]. In this study, instruments were deployed on 15 to 20 individuals each year for a seven-year period to provide an adequate sample size to account for individual variation, tag loss and instrument error. Among the 81 grey seals with adequate data, we found wide variation in their use of space, particularly during the summer period (range of the summer 95\% homerange: $\sim 5000 \mathrm{~km}^{2}$ ). Although we feel confident that our measures of space-use by female grey seals is representative of the population $(n=60)$, we remain cautious with our estimates of home-range size for males $(n=21)$.

Male grey seals had a larger home-range and core area than females in both the summer and fall seasons. This finding agrees with earlier studies showing that male grey seals where more likely to be directed movers, i.e. exhibiting strong linearity in their movement with long path lengths and exploiting large patches of habitat, while females tended to be residents exploiting smaller patches of habitat closer to Sable Island [35, 63]. Sexspecific differences in movement have been found in other sexually dimorphic mammals: adult male ungulates spend more time walking while females (both lactating and non-lactating) spend more time foraging, and these differences are more pronounced with increasing sexual dimorphism [69]. Strong seasonal sexual segregation has also been demonstrated in the Sable Island grey seal population [34] which likely further contributes toward differences in home-range size. It has been suggested that males may be avoiding areas where females forage to reduce intraspecific competition [51], but this remains to be tested.

Grey seals are sexually size dimorphic with males $\sim 1.4$ times heavier than females [38]. Generally, given the relationship between body mass and metabolic rate [70], one expects larger individuals to have greater nutritional requirements and thus larger home-ranges [71]. Males also have a larger gut capacity and can consume a greater amount and diversity of low energy dense prey. In contrast females consume fewer prey species of high 


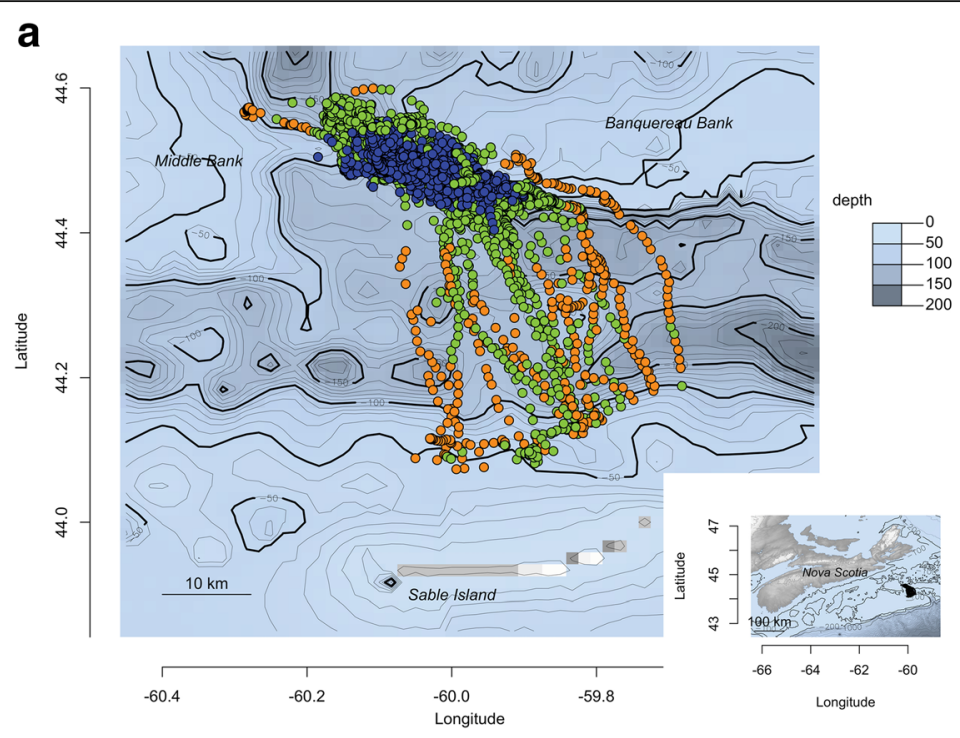

b
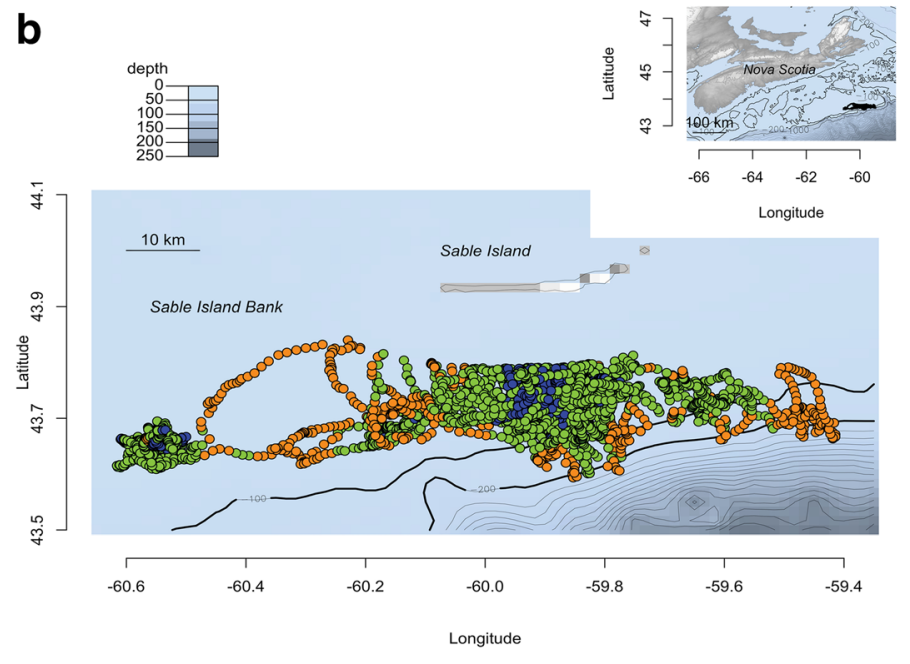

C
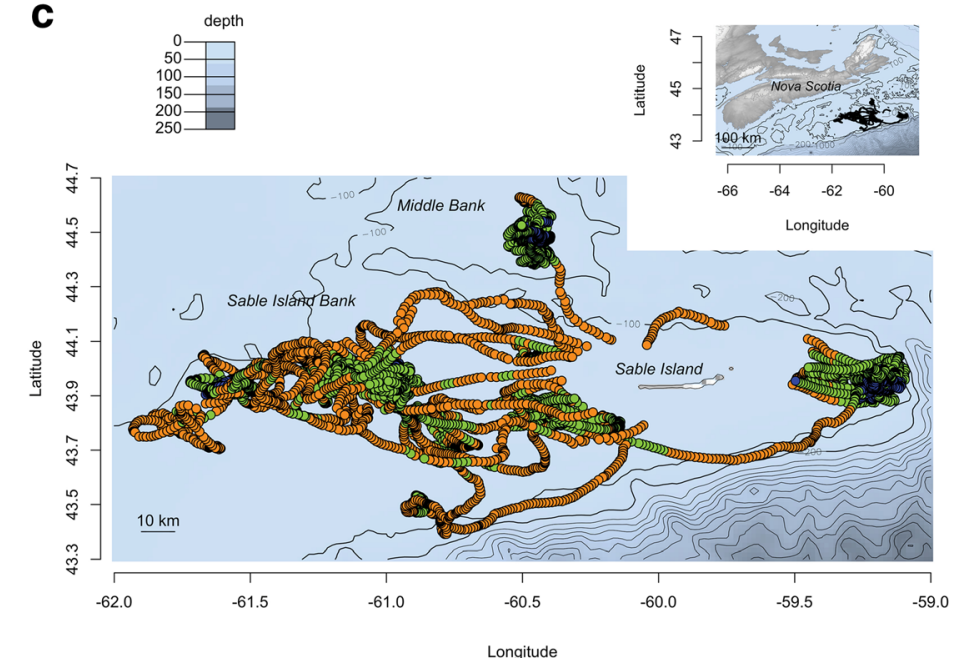

Fig 6 (See legend on next page.) 
(See figure on previous page.)

Fig 6 a-c Examples of movement tracks for three female grey seals on the Eastern Scotian Shelf. Each map shows both broad (map insert) and detailed geographical views of the movement of the seal. Due to their density, GPS locations within $15 \mathrm{~km}$ of Sable Island are not shown on the map. Bathymetry contours (depth, $\mathrm{m}$ ) are given. GPS locations are coloured according to the behavioural categories 1 to 2 (infrequent visits to a hull; dark orange), 3 to 4 (frequent visits to a hull: green) and 5 to 6 (very frequent visits to a hull; blue) (see text for additional description of behavioural categories)

calorific value [42]. This apparent trade-off for forage quantity over quality may contribute to a larger homerange size in males compared to that of females [72].

We found a negative relationship between size of the core area and body mass with larger individuals of both sexes having a smaller area. Home-range size has been shown to vary inversely with the density of food items available [73], thus individuals exploiting higher quality habitat (i.e., high density of prey) may be expected to have a smaller home-range size. Given that intraspecific competition is likely at foraging patches [36], access to higher quality habitat might be limited to those individuals with greater foraging experience and competitive ability, i.e., older, larger individuals. Smaller and less competitive individuals may therefore be limited to lower quality habitat and potentially experience a greater loss of resources to neighbours [71, 74] leading to the use of larger areas.

Both the home range and core area of males and females contracted in the fall (October to early December) with the approach of the breeding season. Sex-specific changes in the fall distribution [34], movement [35], diving behaviour [39, 40], energy storage [38] and diet [42] of grey seals have been previously reported in this population. Grey seals are capital breeders and body mass is an important determinant of reproductive success in both males and females [75-77]. Thus, seasonal changes in the use of space may indicate that both sexes become more selective in their diets by perhaps targeting higherquality prey patches to accumulate sufficient energy reserves to support the high energetic demands of reproduction. Beck et al. [42] have shown that the energy density of prey in male grey seals increases from the spring to fall/early winter.

Other studies have examined site and habitat use patterns in pinnipeds, but only at a coarse scale of resolution [5, 14, 32, 78-83]. A primary reason for choosing $\mathrm{T}-\mathrm{LoCoH}$ to evaluate foraging behaviour and habitat use in this study was its ability to generate temporal indices of site use and allow us to examine movement at a fine spatio-temporal scale. Using the frequency of visits to a hull (a proxy for site fidelity) and the number of locations within a hull (a measure of duration), and along with behavioural and environmental attributes, we have been able to partition the home-range of grey seals according to the nature of its use [54]. Although sex accounted for significant variation in home-range size, it was not a useful predictor of fine-scale site use, suggesting that individual variability may dominate movement behaviour at this fine-scale. Börger et al. [18] found that sex and age in roe deer (Capreolus capreolus) became less important predictors of behaviour with a finer scale analysis of home-range size.

Two key findings were apparent in our fine-scale spatio-temporal data. Locations that were grouped into categories 1 and 2 had few return visits, exhibited linear movement behaviour (high eccentricity and low pARS) and tended to occur between Sable Island and offshore banks (e.g., Middle, French, Canso and Sable Bank). Earlier studies have proposed that these areas are important for foraging in grey seals [34-36, 51, 63]. Given their strong directionality, these movements may reflect memory of the direction to foraging areas and/or the use of perceptual cues [84-86]. Although the habitat along these pathways appears to be of little value to grey seals due to the low number of repeat visits, it does provide access to valuable resources and may do so in a manner that minimises energy expenditure or risks of predation [87].

The second key finding concerned locations that were grouped into categories 5 and 6 . These locations had many return visits, exhibited non-oriented movement [86] and tended to occur on or close to offshore banks. Non-oriented movement is likely to occur when the behaviour of an animal is influenced by sensory stimuli within its immediate environment, e.g. the presence of prey, leading to frequent turns and slow velocity, i.e. area-restricted search [88-90]. Benthic habitats tend to exhibit lower variability in productivity compared with pelagic environments $[4,91]$, thus one may expect capital breeders that need to ensure optimal mass gain prior to the breeding season, to exhibit strong site fidelity to specific foraging areas $[5,14,79,81-83,92]$. Further, maintaining fidelity to specific areas despite variation in prey availability among years, may confer higher fitness in the long term $[5,11,12,14]$. Grey seals also spent relatively more time in these high resource habitats during the fall compared to the summer. Thus, together with increasing their foraging effort during the few months prior to the breeding season $[38,40]$, grey seals also focus their foraging effort in areas that offer high resource value. 
One may expect individuals that spend a large proportion of their time at sea in high resource areas to exhibit a high rate of mass gain. Studies on seabirds and pinnipeds have linked positive gains in body mass or lipid content with the location of foraging and the time spent foraging $[66,93]$. However, in this study the size of the core area nor the proportion of time spent in locations with a high frequency of return visits were important for predicting body mass gain (a proxy for foraging success). This suggests that for grey seals time spent in apparent foraging behaviour is less important than the quality of the foraging patch or that our measure of apparent foraging overestimates foraging effort. Preliminary data from animal-borne cameras from another study has shown that grey seals from Sable Island rest on the sea-floor during trips to sea (unpublished data, Damian C. Lidgard). Thus, it is possible that locations with a high frequency of return visits were also used for resting. Although records of diving behaviour were available for this study, without data from accelerometers and/or animal-borne cameras, dive records alone are inadequate for distinguishing between resting on the sea floor and foraging.

Understanding how animals use space on a fine-scale provides opportunities to explore individual variation in foraging tactics and the consequences of foraging success on fitness $[12,94,95]$. Further, identifying the drivers of intraspecific variation in movement patterns could improve our ability to predict changes in foraging distribution in response to both natural and man-made environmental forcing $[27,96,97]$.

\section{Conclusion}

We have provided a greater understanding of how grey seals use space through incorporating time into home-range analyses. We differentiated areas within the home-range according to the intensity of use and identified high-resource areas. Season, sex and body mass were important predictors of the size of the 95\% and core home-range area, however they were less influential in predicting the time spent in areas with high visitation suggesting substantial individual variation in behaviour at this fine-scale. The size of the core-area nor the time spent in areas with high visitation were good predictors of the gain in body mass suggesting behaviours other than foraging were likely occurring in these heavily-used areas.

Thus, although the metrics used in this study were helpful to identify foraging behaviour in grey seals, one must be cautious when making inferences about behaviour from movement data alone [98]. Studies on freeranging pinnipeds using data collected by head-mounted accelerometers or in situ video will be needed to validate inferences about the at-sea behaviours of these uppertrophic level marine predators.

\section{Supplementary information}

Supplementary information accompanies this paper at https://doi.org/10. 1186/s40462-020-0196-y.

Additional file 1. Metadata of grey seals used in the study, 2009 to 2011, and 2013 to 2015.

Additional file 2. Parameter estimates of chosen linear mixed-effects model with fixed effects.

Additional file 3. Parameter estimates of chosen linear mixed-effects model with fixed effects.

Additional file 4. Parameter estimates of chosen linear mixed-effects model with fixed effects.

Additional file 5. Descriptive measures of hull visitation and duration of stay within a hull for behavioural categories 1 to 6 .

Additional file 6. A Parameter estimates of chosen linear mixed-effects model with fixed effects. B Parameter estimates of chosen linear mixedeffects model with fixed effects.

\section{Abbreviations}

ER: Evidence Ratio; GPS: Global Positioning System; HMM: Hidden Markov Model; pARS: Probability of Area Restricted Search; T-LoCoH: Time-Local Convex Hull

\section{Acknowledgements}

We are grateful to Deborah Austin, Greg Breed, Suzanne Budge, Bob Farmer, Nell den Heyer, Susan Heaslip, Warren Joyce, Shelley Lang, Paul LeBlanc, Elizabeth Leadon, Chad McEwan, Jim McMillan, Rob Ronconi, Heather Smith, Sean Smith, John Tremblay, Megan Wilson and Sarah Wong for assistance in the field. We are also grateful for infrastructure support provided on Sable Island by Environment Canada and Parks Canada. We would like to thank lan Jonsen for developing the Hidden Markov Model, Joanna Mills-Flemming for statistical guidance, Kim Whoriskey for help with graphics and Andy Lyons for assistance using T-LoCoH.

\section{Authors' contributions}

DCL was involved in securing funds for the study, the design of the study and collected and analysed the data. DCL provided all text and graphics for the manuscript. WDB was involved in securing funds for the study, the design of the study, data collection and provided guidance on analysis of the data. SJI was involved in securing funds for the study, the design of the study and provided editorial guidance on a draft manuscript. All authors read and approved the final manuscript.

\section{Funding}

The study was supported through a Research Network Grant (NETGP 375118-08) from the Natural Sciences and Engineering Research Council (NSERC) of Canada, and funds from the Canadian Foundation for Innovation (\#30200) and Department of Fisheries and Oceans, Canada.

The role of these funding bodies was limited to providing funds and were not involved in the design of the study, data collection, analysis,

interpretation of data nor in writing the manuscript.

\section{Availability of data and materials}

Data from this study supporting the conclusions of this article are archived with the Ocean Tracking Network (http://oceantrackingnetwork.org/). Access to these data is available from the corresponding author on reasonable request.

\section{Ethics approval and consent to participate}

All procedures used on study animals adhered to guidelines for the use of animals in research [99] and to the legal requirements of Canada under the Canadian Council of Animal Care (animal care protocols: 08-88, 10-065, 12064 and 14-035, University Committee on Laboratory Animals, Dalhousie University, Halifax NS; 08-16, 10-03, 11-10, 12-13, 14-19 Department of Fisheries and Oceans, Canada). 


\section{Competing interests}

The authors declare that they have no competing interests.

Received: 21 November 2019 Accepted: 5 February 2020 Published online: 13 February 2020

\section{References}

1. Rose GA, Leggett WC. The importance of scale to predator-prey spatial correlations: an example of Atlantic fishes. Ecology. 1990;71:33-43. https:// doi.org/10.2307/1940245

2. Sih A. The behavioral response race between predator and prey. Am Nat. 2002;123:143-50. https://doi.org/10.1086/284193.

3. MacArthur RH, Pianka ER. On optimal use of a patchy environment. Am Nat. 1966;100:603-9. https://doi.org/10.1086/282454.

4. Costa DP, Kuhn CE, Weise MJ, Shaffer SA, Arnould JPY. When does physiology limit the foraging behaviour of freely diving mammals? Int Congr Ser. 2004;1275:359-66. https://doi.org/10.1016/j.ics.2004.08.058.

5. Chilvers BL. Foraging site fidelity of lactating New Zealand Sea lions. J Zool. 2008;276:28-36. https://doi.org/10.1111/j.1469-7998.2008.00463.x.

6. McHuron EA, Robinson PW, Simmons SE, Kuhn CE, Fowler M, Costa DP. Foraging strategies of a generalist marine predator inhabiting a dynamic environment. Oecologia. 2016;182:995-1005. https://doi.org/10.1007/s00442-016-3732-0.

7. Pyke GH. Optimal foraging theory: a critical review. Annu Rev Ecol Syst. 1984:15:523-75. https://doi.org/10.1146/annurev.es.15.110184.002515.

8. Ofstad EG, Herfindal I, Solberg EJ, Sæther BE. Home ranges, habitat and body mass: simple correlates of home range size in ungulates. Proc Biol Sci. 2016;283:20161234. https://doi.org/10.1098/rspb.2016.1234.

9. Fryxell JM, Hazell M, Borger L, Dalziel BD, Haydon DT, Morales JM, Mclntosh T, Rosatte RC. Multiple movement modes by large herbivores at multiple spatiotemporal scales. Proc Natl Acad Sci. 2008;105:19114-9. https://doi.org/ 10.1073/pnas.0801737105.

10. Nathan R, Getz WM, Revilla E, Holyoak M, Kadmon R, Saltz D, Smouse PE. A movement ecology paradigm for unifying organismal movement research. Proc Natl Acad Sci. 2008;105:19052-9. https://doi.org/10.1073/pnas.0800375105.

11. Forrester TD, Casady DS, Wittmer HU. Home sweet home: fitness consequences of site familiarity in female black-tailed deer. Behav Ecol Sociobiol. 2015:69:603-12. https://doi.org/10.1007/s00265-014-1871-z.

12. Patrick SC, Weimerskirch $\mathrm{H}$. Reproductive success is driven by local site fidelity despite stronger specialisation by individuals for large-scale habitat preference. J Anim Ecol. 2017;86:674-82. https://doi.org/10.1111/ 1365-2656.12636.

13. Rolandsen CM, Solberg EJ, Saether B-E, Van Moorter B, Herfindal I, Bjørneraas K. On fitness and partial migration in a large herbivore migratory moose have higher reproductive performance than residents. Oikos. 2017;126:547-55. https://doi.org/10.1111/oik.02996

14. Mclntyre T, Bester MN, Bornemann H, Tosh CA, de Bruyn PJN. Slow to change? Individual fidelity to three-dimensional foraging habitats in southern elephant seals, Mirounga leonina. Anim Behav. 2017:127:91-9. https://doi.org/10.1016/j.anbehav.2017.03.006.

15. Hamilton WJ. Activity and home range of the field mouse, Microtus pennsylvanicus pennsylvanicus. Ecology. 1937;18:255-63. https://doi.org/10. 2307/19304641.

16. Burt WH. Territoriality and home range concepts as applied to mammals. J Mammal. 1943;24:346. https://doi.org/10.2307/1374834

17. Warton BJ. A review of models of home range for animal movement. Ecol Modell. 1987;38:277-98. https://doi.org/10.1016/0304-3800(87)90101-3.

18. Börger L, Franconi N, Ferretti F, Meschi F, Michele GD, Gantz A, Coulson T. An integrated approach to identify spatiotemporal and individual-level determinants of animal home range size. Am Nat. 2006;168:471-85. https:// doi.org/10.1086/507883.

19. Laver PN, Kelly MJ. A critical review of home range studies. J Wildl Manag. 2008;72:290-8. https://doi.org/10.2193/2005-589.

20. Wiens JA. Spatial scaling in ecology. Funct Ecol. 1989;3:385. https://doi.org/ $10.2307 / 2389612$

21. Levin SA. The problem of pattern and scale in ecology. Ecology. 1992;73: 1943-67. https://doi.org/10.2307/1941447.

22. Powell RA, Mitchell MS. What is a home range? J Mammal. 2012;93:948-58. https://doi.org/10.1644/11-MAMM-S-177.1.

23. Dujon AM, Lindstrom RT, Hays GC. The accuracy of Fastloc-GPS locations and implications for animal tracking. Methods Ecol Evol. 2014:5:1162-9. https://doi.org/10.1111/2041-210X.12286.
24. Leblond M, St-Laurent MH, Côté SD. Caribou, water, and ice - fine-scale movements of a migratory arctic ungulate in the context of climate change. Mov Ecol. 2015;4:1-12. https://doi.org/10.1186/s40462-016-0079-4.

25. Sepúlveda M, Pelican K, Cross P, Eguren A, Singer R. Fine-scale movements of rural free-ranging dogs in conservation areas in the temperate rainforest of the coastal range of southern Chile. Mamm Biol. 2015;80:290-7. https:// doi.org/10.1016/j.mambio.2015.03.001

26. Bateman AW, Lewis MA, Gall G, Manser MB, Clutton-Brock TH. Territoriality and home-range dynamics in meerkats, Suricata suricatta: a mechanistic modelling approach. J Anim Ecol. 2015;84:260-71. https://doi.org/10.1111/ 1365-2656.12267.

27. Jones EL, Sparling CE, McConnell BJ, Morris CD, Smout S. Fine-scale harbour seal usage for informed marine spatial planning. Sci Rep. 2017:7:1-11. https://doi.org/10.1038/s41598-017-11174-4.

28. Benhamou S, Valeix M, Chamaillé-Jammes S, Macdonald DW, Loveridge AJ. Movement-based analysis of interactions in African lions. Anim Behav. 2014; 90:171-80. https://doi.org/10.1016/j.anbehav.2014.01.030.

29. Keating KA, Cherry S. Modeling utilization distributions in space and time. Ecology. 2009;90:1971-80. https://doi.org/10.1890/08-1131.1.

30. Benhamou S, Riotte-Lambert L. Beyond the utilization distribution: identifying home range areas that are intensively exploited or repeatedly visited. Ecol Model. 2012;227:112-6. https://doi.org/10.1016/j.ecolmodel. 2011.12.015

31. Lyons AJ, Turner WC, Getz WM. Home range plus: a space-time characterization of movement over real landscapes. Mov Ecol. 2013;1:1. https://doi.org/10.1186/2051-3933-1-2

32. Arthur B, Hindell M, Bester M, Trathan P, Jonsen I, Staniland I, Oosthuizen WC, Wege M, Lea MA. Return customers: foraging site fidelity and the effect of environmental variability in wide-ranging antarctic fur seals. PLOS One. 2015:10:e0120888. https://doi.org/10.1371/journal.pone.0120888.

33. Hammill MO, den Heyer CE, Bowen WD, Lang SLC (2017) Grey seal population trends in Canadian waters, 1960-2016 and harvest advice. DFO Can Sci Advis Sec Res Doc. 2017/052.

34. Breed GA, Bowen WD, McMillan JI, Leonard ML. Sexual segregation of seasonal foraging habitats in a non-migratory marine mammal. Proc R Soc B Biol Sci. 2006:273:2319-26. https://doi.org/10.1098/rspb.2006.3581.

35. Breed GA, Jonsen ID, Myers RA, Don Bowen W, Leonard ML. Sex-specific, seasonal foraging tactics of adult grey seals (Halichoerus grypus) revealed by statespace analysis. Ecology. 2009;90:3209-21. https://doi.org/10.1890/07-1483.1.

36. Lidgard DC, Bowen WD, Jonsen ID, Iverson SJ. Animal-borne acoustic transceivers reveal patterns of at-sea associations in an upper-trophic level predator. PLoS One. 2012;7:e48962. https://doi.org/10.1371/journal.pone.0048962.

37. Austin D, Bowen WD, Mcmillan Jl, Iverson SJ. Linking movement, diving, and habitat to foraging success in a large marine predator. Ecology. 2016; 87:3095-108.

38. Beck CA, Bowen WD, Iverson SJ. Sex differences in the seasonal patterns of energy storage and expenditure in a phocid seal. J Anim Ecol. 2003:72:280_ 91. https://doi.org/10.1046/j.1365-2656.2003.00704.x.

39. Beck CA, Bowen WD, McMillan Jl, Iverson SJ. Sex differences in diving at multiple temporal scales in a size-dimorphic capital breeder. J Anim Ecol. 2003;72:979-93. https://doi.org/10.1046/j.1365-2656.2003.00761.x

40. Beck CA, Don Bowen W, McMillan Jl, Iverson SJ. Sex differences in the diving behaviour of a size-dimorphic \ncapital breeder: the grey seal. Anim Behav. 2003;66:777-89. https://doi.org/10.1006/anbe.2002.2284.

41. Beck CA, Iverson SJ, Bowen WD. Blubber fatty acids of gray seals reveal sex differences in the diet of a size-dimorphic marine carnivore. Can J Zool. 2005:83:377-88. https://doi.org/10.1139/z05-021.

42. Beck CA, Iverson SJ, Bowen WD, Blanchard W. Sex differences in grey seal diet reflect seasonal variation in foraging behaviour and reproductive expenditure: evidence from quantitative fatty acid signature analysis. J Anim Ecol. 2007;76:490-502. https://doi.org/10.1111/j.1365-2656.2007.01215.x.

43. Austin D, Bowen WD, McMillan Jl, Boness DJ. Stomach temperature telemetry reveals temporal patterns of foraging success in a free-ranging marine mammal. J Anim Ecol. 2006;75:408-20. https://doi.org/10.1111/j. 1365-2656.2006.01057.x.

44. Breed GA, Bowen WD, Leonard ML. Development of foraging strategies with age in a long-lived marine predator. Mar Ecol Prog Ser. 2011;431:26779. https://doi.org/10.3354/meps09134

45. Getz WM, Wilmers CC. A local nearest-neighbor convex-hull construction of home ranges and utilization distributions. Ecography. 2004:27:489-505. https://doi.org/10.1111/j.0906-7590.2004.03835.x. 
46. Getz WM, Fortmann-Roe S, Cross PC, Lyons AJ, Ryan SJ, Wilmers CC. LoCoH: Nonparameteric kernel methods for constructing home ranges and utilization distributions. PLoS One. 2007;2:e207. https://doi.org/10.1371/ journal.pone.0000207.

47. DFO. State of the Eastern Scotian Shelf Ecosystem DFO Can Sci Advis Sec Ecosystem Status Report. 2003:2003/004

48. Boness DJ, Bowen WD, Oftedall OT. Evidence of a maternal foraging cycle resembling that of otariid seals in a small phocid, the harbor seal. Behav Ecol Sociobiol. 1994;34:95-104. https://doi.org/10.1007/BF00164180.

49. Hazel J. Evaluation of fast-acquisition GPS in stationary tests and fine-scale tracking of green turtles. J Exp Mar Bio Ecol. 2009;374:58-68. https://doi.org/ 10.1016/j.jembe.2009.04.009.

50. Bryant $\mathrm{E}$ (2007) 2D location accuracy statistics for fastloc cores running firmware versions 2.2 \& 2.3. Technical report TR01. Wildtrack telemetry systems Itd.

51. Breed GA, Don Bowen W, Leonard ML. Behavioral signature of intraspecific competition and density dependence in colony-breeding marine predators. Ecol Evol. 2013;3:3838-54. https://doi.org/10.1002/ece3.754.

52. Hanif M, Sami F, Hyder M, Ch MI. Hidden markov model for time series prediction. J Asian Sci Res. 2017;7:196-205. https://doi.org/10.18488/journal. 2.2017.75.196.205.

53. Brown DR, Sherry TW. Solitary winter roosting of ovenbirds in core foraging area. Wilson J Ornithol. 2008;120:455-9. https://doi.org/10.1676/07-084.1.

54. Schweiger AK, Schütz M, Anderwald $P$, Schaepman ME, Kneubühler $M$, Haller R, Risch AC. Foraging ecology of three sympatric ungulate species behavioural and resource maps indicate differences between chamois, ibex and red deer. Mov Ecol. 2015;3:6. https://doi.org/10.1186/s40462-015-0033-x.

55. Pante E, Simon-Bouhet B. Marmap: a package for importing, plotting and analyzing bathymetric and topographic data in R. PLoS One. 2013;8:e73051. https://doi.org/10.1371/journal.pone.0073051.

56. Bates $D$, Mächler $M$, Bolker $B$, Walker $S$. Fitting linear mixed-effects models using Ime4. J stat Softw. 2014;67:1-48. https://doi.org/10.18637/jss.v067.i01.

57. Burnham KP, Anderson DR, Huyvaert KP. AIC model selection and multimodel inference in behavioral ecology: some background, observations, and comparisons. Behav Ecol Sociobiol. 2011;65:23-35. https:// doi.org/10.1007/s00265-010-1029-6.

58. Garamszegi LZ. Information-theoretic approaches to statistical analysis in behavioural ecology: an introduction. Behav Ecol Sociobiol. 2011;65:1-11. https://doi.org/10.1007/s00265-010-1028-7.

59. Nakagawa $S$, Schielzeth $H$. A general and simple method for obtaining $R^{2}$ from generalized linear mixed-effects models. Methods Ecol Evol. 2013;4: 133-42. https://doi.org/10.1111/j.2041-210x.2012.00261.x.

60. Lefcheck JS. piecewiseSEM: piecewise structural equation modelling in $r$ for ecology, evolution, and systematics. Methods Ecol Evol. 2016;7:573-9. https://doi.org/10.1111/2041-210X.12512.

61. Development Core Team R. R: a language and environment for statistical computing. Vienna, Austria: R Foundation for Statistical Computing; 2007. http://www.R-project.org/

62. Fieberg J, Börger L. Could you please phrase "home range" as a question? J Mammal. 2012;93:890-902. https://doi.org/10.1644/11-MAMM-S-172.1.

63. Austin D, Bowen WD, McMillan Jl. Intraspecific variation in movement patterns: modeling individual behaviour in a large marine predator. Oikos. 2004;105:15-30. https://doi.org/10.1111/j.0030-1299.1999.12730.x.

64. Kie JG, Matthiopoulos J, Fieberg J, Powell RA, Cagnacci F, Mitchell MS, Gaillard JM, Moorcroft PR. The home-range concept: are traditional estimators still relevant with modern telemetry technology? Philos Trans $\mathrm{R}$ Soc B Biol Sci. 2010;365:2221-31. https://doi.org/10.1098/rstb.2010.0093.

65. den Heyer CE, Bowen WD, Mcmillan J. Long-term changes in grey seal vital rates at Sable Island estimated from POPAN mark-resighting analysis of branded seals. DFO Can Sci Advis Sec Res Doc. 2014;2013/021:26

66. Thums M, Rossendell J, Guinea M, Ferreira L. Horizontal and vertical movement behaviour of flatback turtles and spatial overlap with industrial development. Mar Ecol Prog Ser. 2018;602:237-53. https://doi.org/10.3354/meps12650.

67. Gutowsky SE, Leonard ML, Conners M, Shaffer SA, Jonsen ID. Individual-level variation and higher-level interpretations of space-use in wide-ranging species: an albatross case study of sampling effects. Front Mar Sci. 2015;2:93. https://doi.org/10.3389/fmars.2015.00093.

68. Sequeira AMM, Heupel MR, Lea M-A, Eguíluz VM, Duarte CM, Meekan MG, Thums M, Calich HJ, Carmichael RH, Costa DP, Ferreira LC, Fernandéz-Gracia J, Harcourt R, Harrison A-L, Jonsen I, McMahon CR, Sims DW, Wilson RP, Hays GC. The importance of sample size in marine megafauna tagging studies. Ecol Appl. 2019;29:e01947. https://doi.org/10.1002/eap.1947.
69. Ruckstuhl KE, Neuhaus P. Sexual segregation in ungulates: a comparative test of three hypotheses. Biol Rev Camb Philos Soc. 2002;77:77-96. https:// doi.org/10.1017/S1464793101005814.

70. Kleiber M. The fire of life: an introduction to animal energetics. New York: London: John Wiley \& Sons, Inc; 1961.

71. Jetz W, Carbone C, Fulford J, Brown JH. The scaling of animal space use Science. 2004;306:266-8. https://doi.org/10.1126/science.1102138.

72. Cederlund $\mathrm{G}$, Sand $\mathrm{H}$. Home-range size in relation to age and sex in moose. J Mammal. 1994;75:1005-12. https://doi.org/10.2307/1382483.

73. South A. Extrapolating from individual movement behaviour to population spacing patterns in a ranging mammal. Ecol Model. 1999;117:343-60. https://doi.org/10.1016/S0304-3800(99)00015-0.

74. Rosten CM, Gozlan RE, Lucas MC. Allometric scaling of intraspecific space use. Biol Lett. 2016;12:20150673. https://doi.org/10.1098/rsbl.2015.0673.

75. Mellish JE, Iverson SJ, Bowen WD. Variation in milk production and lactation performance in grey seals and consequences for pup growth and weaning characteristics. Physiol Biochem Zool. 1999;72:677-90. https://doi.org/10. 1086/316708

76. Lidgard DC, Boness DJ, Bowen WD, McMillan Jl. State-dependent male mating tactics in the grey seal: the importance of body size. Behav Ecol. 2005;16:541-9. https://doi.org/10.1093/beheco/ari023.

77. Bowen WD, den Heyer CE, Mcmillan JI, Iverson SJ. Offspring size at weaning affects survival to recruitment and reproductive performance of primiparous gray seals. Ecol Evol. 2015;5:1412-24. https://doi.org/10.1002/ece3.1450.

78. Bonadonna F, Lea MA, Dehorter O, Guinet C. Foraging ground fidelity and routechoice tactics of a marine predator: the Antarctic fur seal Arctocephalus gazella. Mar Ecol Prog Ser. 2001;223:287-97. https://doi.org/10.3354/meps223287.

79. Bradshaw CJA, Hindell MA, Sumner MD, Michael KJ. Loyalty pays: potential life history consequences of fidelity to marine foraging regions by southern elephant seals. Anim Behav. 2004;68:1349-60. https://doi.org/10.1016/j. anbehav.2003.12.013.

80. Lowther AD, Harcourt RG, Hamer DJ, Goldsworthy SD. Creatures of habit: foraging habitat fidelity of adult female Australian sea lions. Mar Ecol Prog Ser. 2011;443:249-63. https://doi.org/10.3354/meps09392.

81. Authier M, Bentaleb I, Ponchon A, Martin C, Guinet C. Foraging fidelity as a recipe for a long life: foraging strategy and longevity in male southern elephant seals. PLoS One. 2012;7:e32026. https://doi.org/10.1371/journal. pone.0032026.

82. Baylis AMM, Page B, McKenzie J, Goldsworthy SD. Individual foraging site fidelity in lactating New Zealand fur seals: continental shelf vs. oceanic habitats. Mar Mammal Sci. 2012;28:276-94. https://doi.org/10.1111/j.17487692.2011.00487.x

83. Wege M, Tosh CA, De Bruyn PJN, Bester MN. Cross-seasonal foraging site fidelity of subantarctic fur seals: implications for marine conservation areas. Mar Ecol Prog Ser. 2016;554:225-39. https://doi.org/10.3354/meps11798.

84. Fagan WF, Lewis MA, Auger-Méthé M, Avgar T, Benhamou S, Breed G, Ladage L, Schlägel UE, Tang WW, Papastamatiou YP, Forester J, Mueller T. Spatial memory and animal movement. Ecol Lett. 2013;16:1316-29. https:// doi.org/10.1111/ele.12165

85. Bracis C, Mueller T. Memory, not just perception, plays an important role in terrestrial mammalian migration. Proc R Soc B Biol Sci. 2017;284:20170449. https://doi.org/10.1098/rspb.2017.0449.

86. Mueller T, Fagan WF. Search and navigation in dynamic environments from individual behaviors to population distributions. Oikos. 2008;117:65464. https://doi.org/10.1111/j.0030-1299.2008.16291.x.

87. Wirsing AJ, Heithaus MR, Dill LM. Fear factor: do dugongs (Dugong dugon) trade food for safety from tiger sharks (Galeocerdo cuvier)? Oecologia. 2007; 153:1031-40. https://doi.org/10.1007/s00442-007-0802-3.

88. Benhamou S, Bovet P. How animals use their environment: a new look at kinesis. Anim Behav. 1989;38:375-83. https://doi.org/10.1016/S00033472(89)80030-2.

89. Weimerskirch H, Pinaud D, Pawlowski F, Bost C. Does prey capture induce area-restricted search? A fine-scale study using GPS in a marine predator, the wandering albatross. Am Nat. 2007;170:734-43. https://doi.org/10.1086/ 522059

90. Dias MP, Granadeiro JP, Palmeirim JM. Searching behaviour of foraging waders: does feeding success influence their walking? Anim Behav. 2009;77: 1203-9. https://doi.org/10.1016/j.anbehav.2009.02.002.

91. Costa DP, Gales NJ. Energetics of a benthic diver: seasonal foraging ecology of the Australian Sea lion, Neophoca cinerea. Ecol Monogr. 2003;73:27-43. https://doi.org/10.1890/0012-9615(2003)073[0027:EOABDS]2.0.CO;2. 
92. Lowther AD, Harcourt RG, Goldsworthy SD, Stow A. Population structure of adult female Australian sea lions is driven by fine-scale foraging site fidelity. Anim Behav. 2012;83:691-701. https://doi.org/10.1016/j.anbehav.2011.12.015.

93. Schick R, New L, Thomas L, Costa D, Hindell M, McMahon C, Robinson P, Simmons S, Thums M, Harwood J, Clark J. Estimating resource acquisition and at-sea body condition of a marine predator. J Anim Ecol. 2013;82:130015. https://doi.org/10.1111/1365-2656.12102 .

94. Bolnick DI, Svanbäck R, Fordyce JA, Yang LH, Davis JM, Hulsey CD, Forister ML. The ecology of individuals: incidence and implications of individual specialization. Am Nat. 2003;161:1-28. https://doi.org/10.1086/343878.

95. Patrick SC, Weimerskirch H. Personality, foraging and fitness consequences in a long lived seabird. PLoS One. 2014;9:e87269. https://doi.org/10.1371/ journal.pone.0087269.

96. Allen AM, Mansson J, Sand H, Malmsten J, Ericsson G, Singh NJ. Scaling up movements: from individual space use to population patterns. Ecosphere. 2016;7:e01524. https://doi.org/10.1002/ecs2.1524.

97. Jones EL, Hastie GD, Smout S, Onoufriou J, Merchant ND, Brookes KL, Thompson D. Seals and shipping: quantifying population risk and individual exposure to vessel noise. J Appl Ecol. 2017;54:1930-40. https://doi.org/10. 1111/1365-2664.12911.

98. Carter MID, Bennett KA, Embling CB, Hosegood PJ, Russell DJF. Navigating uncertain waters: a critical review of inferring foraging behaviour from location and dive data in pinnipeds. Mov Ecol. 2016;4:25. https://doi.org/10. 1186/s40462-016-0090-9.

99. ASAB. Guidelines for the treatment of animals in behavioural research and teaching. Anim Behav. 2018;135:-I-X. https://doi.org/10.1016/.janbehav.2017.10.001.

\section{Publisher's Note}

Springer Nature remains neutral with regard to jurisdictional claims in published maps and institutional affiliations.

Ready to submit your research? Choose BMC and benefit from:

- fast, convenient online submission

- thorough peer review by experienced researchers in your field

- rapid publication on acceptance

- support for research data, including large and complex data types

- gold Open Access which fosters wider collaboration and increased citations

- maximum visibility for your research: over $100 \mathrm{M}$ website views per year

At $\mathrm{BMC}$, research is always in progress.

Learn more biomedcentral.com/submissions 